\title{
Louse-borne relapsing fever (Borrelia recurrentis) in asylum seekers from Eritrea, the Netherlands, July 2015
}

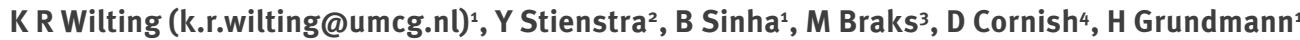

1. Department of Medical Microbiology, University of Groningen, University Medical Center Groningen, the Netherlands

2. Department of Internal Medicine \& Infectious Diseases, University of Groningen, University Medical Center Groningen, the Netherlands

3. National Institute for Public Health and the Environment (RIVM), Bilthoven, the Netherlands

4. National Reception Center for Asylum Seekers (Gezondheidscentrum Asielzoekers), Ter Apel, the Netherlands

Citation style for this article:

Wilting KR, Stienstra Y, Sinha B, Braks M, Cornish D, Grundmann H. Louse-borne relapsing fever (Borrelia recurrentis) in asylum seekers from Eritrea, the Netherlands, July 2015. Euro Surveill. 2015;20(30):pii=21196. Available online: http://www.eurosurveillance.org/ViewArticle.aspx?Articleld=21196

Two patients from Eritrea, recently arrived in the Netherlands, presented with fever and were investigated for malaria. Bloodfilms showed spirochetes but no blood parasites. Louse-borne relapsing fever caused by Borrelia recurrentis was diagnosed. Treatment was complicated by severe Jarisch-Herxheimer reactions in both patients. Physicians should be aware of the possibility of $B$. recurrentis infection in migrant populations who travel under crowded conditions, especially after passing through endemic areas such as Ethiopia and neighbouring countries.

Borrelia recurrentis has for many centuries caused infections of often epidemic proportions known as relapsing fever. Since the infection is exclusively transmitted by body lice and humans are their only host, large scale outbreaks are only expected under circumstances conducive to louse infestation. We here report the first introduction of louse-borne relapsing fever into the Netherlands after World War II.

\section{Case descriptions}

\section{Patient 1}

On 4 July 2015, a young adult from Eritrea was referred from the National Reception Centre for Asylum Seekers (Asielzoekercentrum, AZC) to a regional hospital in the northern Netherlands with a five-day history of headache, dizziness, right upper quadrant pain, myalgia, and fever $\left(39.3^{\circ} \mathrm{C}\right)$. Malaria was suspected. The patient had been in the Netherlands for only two days after arriving in Europe 14 days earlier. En route to Europe, they travelled through Ethiopia, Sudan and Libya. Previously, they had noticed chills while sheltering in an unofficial street camp in Rome where they stayed with a small group of fellow Eritreans before travelling to the Netherlands.

Thick and thin bloodfilms did not show malaria parasites and commercial malaria antigen tests were negative. However, filamentous unidentified structures were reported in the thick film by the laboratory of the peripheral hospital. The patient received empirical treatment with a single dose of ceftriaxone $(2,000$ $\mathrm{mg}$ intravenously) for suspected bacterial septicaemia. After administration, their condition deteriorated and the patient was transferred within the next two hours to the University Medical Center Groningen (UMCG) where they arrived at the emergency department with headache, peripheral hypothermia $\left(35.3^{\circ} \mathrm{C}\right)$, hypotension (systolic/diastolic blood pressure $78 / 52 \mathrm{mmHg}$, heart rate of 106 beats per minute), abdominal pain but no hepatosplenomegaly, and shortness of breath (respiratory rate 23 breaths/min).

Laboratory analysis showed leucocytopenia (leucocytes: $1.6 \times 10^{9} / \mathrm{L}$, norm: $4.5-10 \times 10^{9} / \mathrm{L}$ ), anaemia (haemoglobin: $6.5 \mathrm{mmol} / \mathrm{L}$, norm: 8.6-11.2 $\mathrm{mmol} / \mathrm{L}$ ) and thrombocytopenia (thrombocytes: $16 \times 10^{9} / \mathrm{L}$, norm: $150-450 \times 10^{9 / L}$ ). C-reactive protein (CRP) was $254 \mathrm{mg} / \mathrm{L}$ (norm: < $1 \mathrm{mg} / \mathrm{L}$ ). Kidney function was normal. The patient's liver function tests showed mildly elevated transaminases (alanine transaminase: 58 $\mathrm{U} / \mathrm{L}$, norm: 7-56 U/L; aspartate transaminase: 108 $\mathrm{U} / \mathrm{L}$, norm: $10-40 \mathrm{U} / \mathrm{L}$; alkaline phospatase: 124 $\mathrm{U} / \mathrm{L}$, norm 20-140 U/L; gamma-glutamyl transferase: $93 \mathrm{U} / \mathrm{L}$, norm $\mathrm{O}-51 \mathrm{U} / \mathrm{L}$ ) and total bilirubin levels of $38 \mu \mathrm{mol} / \mathrm{L}$ (norm: $<26 \mu \mathrm{mol} / \mathrm{L}$ ) and direct bilirubin $35 \mu \mathrm{mol} / \mathrm{L}$ (norm: $<7 \mu \mathrm{mol} / \mathrm{L}$ ). Oxygen saturation was 91\% (norm: $95-100 \%$ ). Giemsa-stained thick and thin films revealed spirochetes in large numbers (Figure 1) and no malaria parasites.

Given the patient's travel history, louse-borne relapsing fever was suspected. Their clinical deterioration was provoked by the ceftriaxone administration leading to a severe Jarisch-Herxheimer reaction [1]. Treatment was switched to doxycyline $200 \mathrm{mg}$ per day intravenously to reduce the risk of relapse [2]. The patient was transferred to the intensive care unit (ICU) for fluid 


\section{FIGURE 1}

Giemsa-stained thick film from a patient with louse-borne relapsing fever, the Netherlands, 4 July 2015

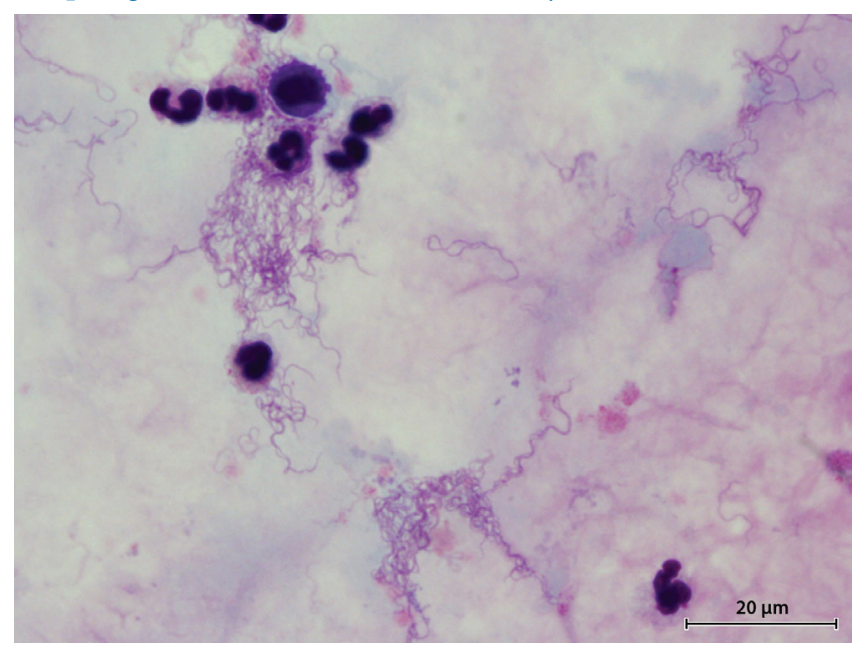

Photograph courtesy of B. Huizinga, Department of Medical Microbiology, University Medical Center Groningen.

\section{FIGURE 2}

Body louse (Pediculus humanus humanus) recovered from the clothing of a patient with louse-borne relapsing fever, the Netherlands, 7 July 2015

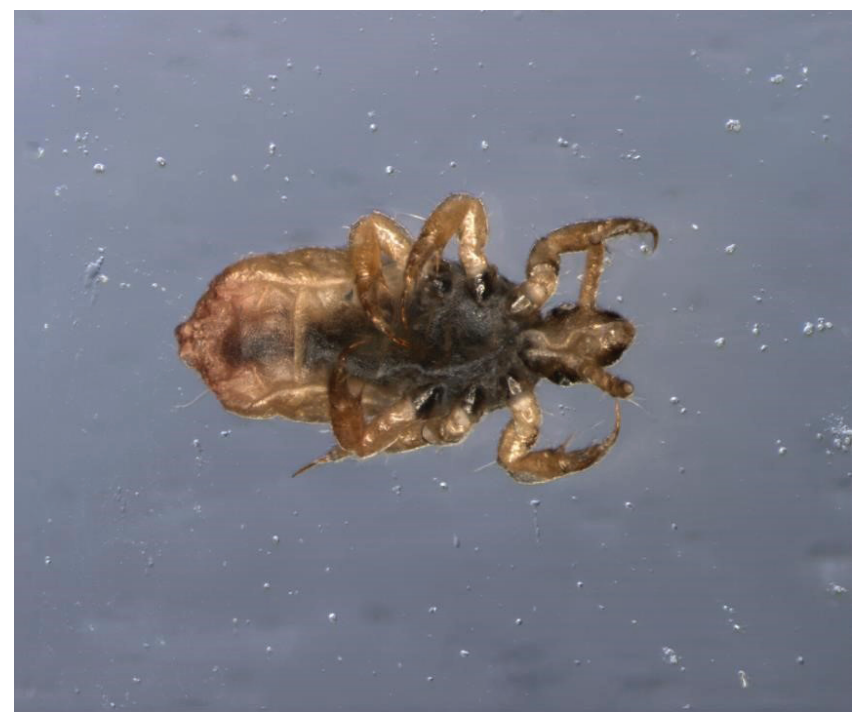

Photograph courtesy of M. Fonville, National Institute for Public Health and the Environment (RIVM).

resuscitation, cardiac support with noradrenalin and supportive oxygen delivery via high flow nose mask. Borrelia recurrentis was confirmed by $16 \mathrm{~S}$ rDNA PCR and sequencing directly from blood two days later. The patient stayed at the ICU for two days, made a full recovery and was discharged after six days. The body louse Pediculus humanus humanus was recovered from their clothing (Figure 2).

\section{Patient 2}

On 9 July 2015, a second young adult from Eritrea was directly referred by the responsible physician at the AZC to the UMCG. On arrival, the patient presented with general malaise, headache, fever $\left(38.5^{\circ} \mathrm{C}\right)$ and cough. Blood tests showed elevated inflammatory parameters (leucocytes: $12.7 \times 10^{9} / \mathrm{L}, \mathrm{CRP}: 320 \mathrm{mg} / \mathrm{L}$ ), normal kidney function and slightly elevated transaminases, but the blood sample was haemolytic. Thick and thin films showed spirochetes and treatment was started with doxycyline $200 \mathrm{mg}$ orally. Two hours later the patient developed a severe Jarisch-Herxheimer reaction which required admission to intensive care where they received fluid resuscitation, inotropic treatment with noradrenalin and oxygen via a face mask. $B$. recurrentis was confirmed by $16 \mathrm{~S}$ rDNA sequencing.

The patient reported symptoms of chills and fever two weeks before presentation at our hospital. Their journey through North Africa followed the same route as that of Patient 1, but Patient 2 had arrived in Europe a week earlier. Patient 2 had camped out in the streets for five days in Rome (as had Patient 1). Patient 2 arrived in the Netherlands two weeks before presenting at our hospitals after travelling through Austria and Germany. The patient made a full recovery and was discharged after five days. Lice could not be recovered from the clothing.

\section{Discussion}

$B$. recurrentis should be suspected in patients presenting with fever and a recent history of migration from or through endemic countries (Ethiopia, Sudan, Eritrea, and Somalia). The infection is transmitted through body lice ( $P$. humanus humanus, formally known as $P$. humanus corporis) which typically lives and breeds in the seams of clothes but can occasionally also be found in bedlinen. Immigrants may share their clothing and that can pose an additional risk of transmission. The incubation period for relapsing fever is usually four to eight days with a range of two to 15 days [3]. It should be noted that head lice ( $P$. humanus capitis) which are not uncommon in Northern Europe are incompetent vectors and cannot transmit $B$. recurrentis. The spirochetes are easily visible under a microscope in a Giemsa-stained thick or thin blood film as used for the diagnosis of Plasmodium spp [4]. In our patients, the diagnosis was confirmed in both cases by 165 rDNA PCR and sequencing from blood.

Published evidence supports a single dose of tetracycline $500 \mathrm{mg}$ intravenously as the conventional treatment, but considering the limited availability of this drug, doxycycline $200 \mathrm{mg}$ can be used as an effective alternative $[2,5]$. In young children, pregnant women, or patients with a tetracycline allergy, erythromycin 500 mg can be used instead [6].

Both patients had travelled independently along a similar route before arriving in the Netherlands. Given the incubation period, it cannot be ruled out that the infection was acquired within Europe. Crucial information about risk factors such as exact travel history, recollection of louse infestation or bites and onset of symptoms was, however, impossible to obtain from our 
patients. Apart from being very sick and the fact that communication required an interpreter versed in Tigre our patients appeared to be traumatised and intimidated and not eager to volunteer information for fear of legal consequences.

Both patients developed a severe Jarisch-Herxheimer reaction after starting antibiotic treatment. $B$. recurrentis evades host immune defences, resulting in very high bacterial loads $\left(10^{6}-10^{8} / \mu \mathrm{l}\right)$, and effective antibiotic therapy is followed by severe reactions characterised by sudden rigors, fever and hypotension in virtually all treated patients [3]. Clinical symptoms are associated with increased plasma concentrations of tumour necrosis factor alpha (TNF-alpha), interleukin-6 and interleukin-8 [7]. Treating physicians should be aware of this complication and the chances that ICU admission may be warranted. It is advised that patients receive two well-placed intravenous lines for rapid fluid resuscitation. Treatment of Jarisch-Herxheimer reaction consists mainly of supportive care. Corticosteroids seem to have limited beneficial effect but studies suggests that TNF-alpha blockers may be useful [8].

An ad hoc survey at the AZC on 16 July found body lice on two newly arrived Eritreans. Since then, all asylum seekers arriving from endemic countries to the $A Z C$ have been segregated into a different compound, where they turn over all of their personal clothes in exchange for disposable overalls. Personal clothes are then washed and returned on the next day. Used overalls and bed linen are subsequently destroyed. In addition to delousing, all arrivals receive a single dose of ivermectin as pre-emptive treatment against scabies and Eritreans who arrive with clinically manifest scabies (about $80 \%$ of all new arrivals) receive a second dose a week later. No new cases of $B$. recurrentis infection have been identified since mandatory delousing was implemented.

\section{Conclusion}

Because infections with $B$. recurrentis pose a significant health risk to other migrants, aid workers, healthcare personnel and arguably to the general population, screening and delousing should be considered for arriving migrants already at ports of entry into the European Union. Our patients may have acquired body lice before arriving in Europe but transmission of infected lice between migrants after arrival in Europe cannot be ruled out and could pose an additional public health challenge.

\section{Acknowledgements}

The contribution of B. Huizinga and M. Fonville to the illustrations are gratefully acknowledged.
Authors' contributions

KRW had responsibility in the clinical management of the patients and wrote the initial manuscript. YS had responsibility in the clinical management of the patients contributed to the collection of epidemiological information. BS carried out diagnostic confirmation. MB carried out the entomological investigation. DC had responsibility in the clinical management at the primary health care level and contributed to the entomological investigation. HG made the tentative diagnosis and wrote the initial manuscript. All authors contributed to the editing of the final manuscript.

\section{References}

1. Loscalzo, Joseph; Fauci, Anthony S.; Braunwald, Eugene Dennis L. Kasper; Hauser, Stephen L; Longo, Dan L. (2008). Harrison's Principles of Internal Medicine. McGraw-Hill Medical. pp. 1048-67. ISBN 0-07-146633-9

2. Guerrier G, Doherty T. Comparison of antibiotic regimens for treating louse-borne relapsing fever: a meta-analysis. Trans R Soc Trop Med Hyg. 2011;105(9):483-90. http://dx.doi. org/10.1016/j.trstmh.2011.04.004 PMID:21803390

3. Bryceson ADM, Parry EHO, Perine PL, Warrell DA, Vukotich D, Leithead CS. Louse-borne relapsing fever. Q J Med. 1970;39(153):129-70. PMID:4913454

4. Versalovic J, Carroll KC, Funke G, Jorgensen JH, Landy ML, Warnock DW. Preparation of thick and thin blood films. In manual of clinical microbiology. pp 2086-2088. AMS press, Washington DC 2011.

5. Perine PL, Awoke S, Krause DW, McDade JE. Single-dose doxycycline treatment of louse-borne relapsing fever and epidemic typhus. Lancet. 1974;304(7883):742-4. http://dx.doi. org/10.1016/S0140-6736(74)90940-4 PMID:4143011

6. Perine PL, Teklu B. Antibiotic treatment of louse-borne relapsing fever in Ethiopia: a report of 377 cases. Am J Trop Med Hyg. 1983;32(5):1096-100.jrn PMID:6625065

7. Butler T, Jones PK, Wallace CK. Borrelia recurrentis infection: single-dose antibiotic regimens and management of the Jarisch-Herxheimer reaction. J Infect Dis. 1978;137(5):573-7. http://dx.doi.org/10.1093/infdis/137.5.573 PMID:659915

8. Fekade D, Knox K, Hussein K, Melka A, Lalloo DG, Coxon RE, et al. Prevention of Jarisch-Herxheimer reactions by treatment with antibodies against tumor necrosis factor alpha. $\mathrm{N}$ Engl J Med. 1996;335(5):311-5. http://dx.doi.org/10.1056/ NEJM199608013350503 PMID:8663853 